\title{
Bronchoalveolar Lavage
}

\section{Walter R. Martin, Philip A. Padrid, and Carroll E. Cross*}

\begin{abstract}
Division of Pulmonary-Critical Care Medicine, University of California, Davis Medical Center,

Sacramento, CA 95817
\end{abstract}

\section{Introduction and Historical Background}

Bronchoalveolar lavage (BAL) was advocated in the late 1950s as a therapeutic measure for dialysis in acute renal failure $(1,2)$. In the 1960 s, Finley and colleagues described increased numbers of neutrophils (PMNs) in BAL fluid recovered from the lungs of smokers $(3,4)$ and Ramirez used BAL in the treatment of alveolar proteinosis (5). The procedure was occasionally employed in patients with cystic fibrosis and with status asthmaticus in order to remove inspissated bronchial secretions, thereby improving gas exchange. Shortly after the introduction of the fiberoptic bronchoscope (FB) in late 1960s, Reynolds, Hunninghake, Crystal and their colleagues at the National Institutes of Health (NIH) developed the technique of BAL as a research tool to study the cell biology of the lower respiratory tract $(6-8)$.

During the $1980 \mathrm{~s}$, wedged placement of a FB into a segmental or subsegmental bronchus facilitated the evolution of the technique of BAL as a clinical method for direct sampling of alveolar contents by simple irrigation of the lung (9-15). Lavaged cells have been shown to fairly accurately reflect the various immune and inflammatory cell types that can be derived from concomitant open lung biopsies (16-18). In spite of this, its utility in clinical decision making has been

*Author to whom all correspondence and reprint requests should be addressed. Clinical Reviews in Allergy, vol. 8 Ed: M. Eric Gershwin 01990 The Humana Press Inc. 
exploited in relatively few specific patient populations, most notably that of immunosuppressed hosts with diffuse $X$-ray infiltrates, including patients with acquired immunodeficiency syndrome (AIDS) (19-22).

It is becoming more generally appreciated that BAL fluid analysis can influence diagnostic reasoning when assessing any number of interstitial lung diseases (23-26). BAL continues to be an extremely useful tool for investigating pathogenetic mechanisms that are operative in pulmonary disorders. This article will focus upon the importance and the limitations of BAL as a useful tool in the study and understanding of respiratory disease.

\section{General Considerations of Clinical Utility}

Although microbiologic analysis of the content of BAL fluid often provides a specific diagnosis in many forms of diffuse or localized infectious pulmonary diseases, the information provided by BAL alone seldom provides information that yields a definitive diagnosis in noninfectious forms of diffuse pulmonary disorders. Table 1 lists some of the disease categories in which evaluation of BAL fluid has also been shown to be diagnostic, helpful, or controversial and in which BAL has been used mainly for research purposes.

\section{Infectious Lung Disease}

In the evaluation of immunocompromised patients whose chest radiographs reveal either diffuse or localized pulmonary infiltrates, $\mathrm{BAL}$ is now the first major diagnostic intervention, even in the presence of acute respiratory failure (19-21,27). In this setting, a high diagnostic yield that will influence patient management strategies is expected $(21,27,28)$. BAL is the procedure of choice when pulmonary tuberculosis is suspected and sputum smears are negative (29). In addition, $\mathrm{BAL}$ is being used with increasing frequency in the diagnosis of infectious pneumonia, particularly in the intensive care unit setting (30).

\section{Noninfectious Diffuse Lung Disease}

BAL plays a less prominent role in the diagnostic armamentarium of the clinician charged with evaluating noninfectious diffuse pulmonary diseases. These diseases comprise a very heterogeneous 
Table 1

Clinical Utility of BAI in Various Lung Diseases

\begin{tabular}{|c|c|c|c|}
\hline $\begin{array}{l}\text { BAl Can Be } \\
\text { Diagnostic }\end{array}$ & BAL Helpful & $\begin{array}{l}\text { of Controversal } \\
\text { fulness }\end{array}$ & $\begin{array}{l}\text { BAI Useful for } \\
\text { Research Purposes }\end{array}$ \\
\hline Infection in the & wung Cancer & Iaiopathic & cigarette \\
\hline Immunocompromised & & Puimonary & Smoke- \\
\hline $\begin{array}{l}\text { Host (incluaing } \\
\text { AIDS) }\end{array}$ & sarcoid & Fibrosis & $\begin{array}{l}\text { Induced Lung } \\
\text { Disease }\end{array}$ \\
\hline & Hypersensitivity & collegen & \\
\hline Tuberculosis & Pneumonitis & $\begin{array}{l}\text { Vascular } \\
\text { Disease }\end{array}$ & ARDS \\
\hline $\begin{array}{l}\text { Pulmonary Alveolar } \\
\text { Proteinosis }\end{array}$ & $\begin{array}{c}\text { Intra-alveolar } \\
\text { Hemorrhagic }\end{array}$ & & Asthma \\
\hline Lipoid Pneumonia & Disorders & & $\begin{array}{c}\text { Lung Responses } \\
\text { to Toxic } \\
\text { substances }\end{array}$ \\
\hline $\begin{array}{l}\text { occupational or } \\
\text { Environmental }\end{array}$ & $\begin{array}{l}\text { Disease } \\
\text { Distiong }\end{array}$ & & r \\
\hline $\begin{array}{l}\text { Exposure to } \\
\text { Inorganic Dusts }\end{array}$ & Lymphoma & & \\
\hline Histiocytosis $x$ & $\begin{array}{l}\text { Lymphargitic } \\
\text { Carcinomatosis }\end{array}$ & & \\
\hline $\begin{array}{r}\text { Eosinophitic } \\
\text { Eneumonias }\end{array}$ & $\begin{array}{l}\text { Immune-related } \\
\text { Pneumonitis } \\
\text { seen following } \\
\text { bone marrow and } \\
\text { lung transplanta }\end{array}$ & ion & \\
\hline
\end{tabular}

group of perhaps 200 interstitial and bronchiolar-alveolar inflammatory processes of lung parenchyma with varying degrees of intensity. Some degree of interstitial fibrosis is almost always present in these cases. These fibrotic processes are believed to be "programmed" by inflammatory-immune effector cells such as alveolar macrophages (AM) and their precursor monocytes, polymorphonuclear leukocytes (PMNs), eosinophils, T- and B-lymphocytes, mast cells and basophils. The fibrotic distortion and thickening of lung interstitium may eventually lead to interference with gas exchange and subsequent respiratory failure.

Analysis of the cellular, protein, and lipid content of BAL fluid affords the clinician the opportunity to qualitatively and quantitatively assess the intensity of parenchyma inflammation occurring in up to a million alveoli from one or more regions of the lung (11). Unlike the classic approach of limited open lung biopsy, analysis of BAL returns permit serial evaluations of current disease activity and progression of inflammation within lung tissue, as well as the ability to monitor response to therapy, in a relatively noninvasive manner $(24-26)$.

There is no consensus on the precise role of $B A L$ in the clinical assessment of the noninfectious diffuse interstitial lung diseases $(8,12,14)$. Although recognition of abnormal numbers of inflamma- 
tory-immune cells as well as the major abnormal cell type present (e.g., lymphocyte or PMN) is often helpful, there is little agreement on whether quantitative assessments of the degree of abnormality present are clinically useful when formulating patient management strategies. For exampie, asymptomatic farmers may have a lymphocytic BAL (31), whereas asymptomatic patients with collagen vascular diseases may have a neutrophilic BAL (32-34). Whereas some of these patients may later develop significant degrees of pulmonary impairment, it is apparent that others may not.

A consensus view would be that BAL is a legitimate clinical tool for the evaluation of patients with diffuse interstitial infiltrates of uncertain etiology. In this regard, BAL is perhaps most useful in distinguishing those disease processes characterized by a predominant lymphocytic BAL from those disease processes in which neutrophilic BAI reactions predominate (Table 2). For example, in a clinical setting in which sarcoid and lymphoma seem unlikely, the finding of a lymphocytic BAL may trigger a more aggressive diagnostic evaluation for environmental allergens that could cause hypersensitivity pneumonitis, particularly if suppressor T-lymphocytes predominated in the BAL fluid.

Routine evaluations of noninfectious diffuse lung disease rely predominantly on clinical history, physical examination, pulmonary function tests, and the chest X-ray. More recently, the diagnostic value of thin-cut chest CTs has been emphasized (35,36). Differences in technical procedures for collecting and processing BAL contents have impeded the widespread routine acceptance of BAL as an established clinical procedure $(15,37)$. At this time, BAL is most useful when integrated with other critical clinical information, including in many instances, the results of transbronchial biopsy.

\section{TeChnical Considerations}

Although a standard protocol for performing BAL and for processing the obtained fluid has not been universally accepted, recent international conferences sponsored by NIH (12) and by a task group on BAL of the European Society of Pneumology (15) have addressed this issue. Following premedication with a sedating compound such as diazepam, together with atropine and inhalations of a beta agonist, the upper airways are generally anesthetized by alocal application of lidocaine. The lidocaine is administered by spray aerosol and direct 
Table 2

Lung Diseases Associated with Mostly Lymphocytic or Mostly Neutrophilic BALS

\begin{tabular}{|c|c|}
\hline Lymphocytic BAI & Neutrophilic BAL \\
\hline Sarcoid & $\begin{array}{c}\text { Idiopathic pulmonary } \\
\text { Fibrosis }\end{array}$ \\
\hline Hypersensitivity Pneumonitis & \\
\hline $\begin{array}{l}\text { Scleroderma associated with } \\
\text { Sjogren's Syndrome } \\
\text { Lymphoma Involving Lung }\end{array}$ & $\begin{array}{l}\text { Most Forms of Connective } \\
\text { Tissue Diseases } \\
\text { (Collagen Vascular } \\
\text { Diseases) }\end{array}$ \\
\hline $\begin{array}{l}\text { HIV-associated Interstitial } \\
\text { Fibrosis }\end{array}$ & $\begin{array}{l}\text { ARDS } \\
\text { Most Lung Bacterial Infections }\end{array}$ \\
\hline $\begin{array}{l}\text { Berylliosis } \\
\text { Granite Workers }\end{array}$ & Most Preumoconioses \\
\hline $\begin{array}{l}\text { Immune-Related Pneumonitis } \\
\text { seen after lung and bone } \\
\text { marrow transplantation }\end{array}$ & \\
\hline
\end{tabular}

instillation to the nasal, oral, and pharyngeal area, plus directinstillation via the bronchoscope to the larynx. Excessive amounts of lidocaine delivered into the lung may influence the results of microbiologic cultures and more importantly, may cause bronchospasm or cardiotoxic if excessive blood levels are reached. Adverse reactions to medication probably account for at least half of the serious morbidity and rare mortalities associated with flexible bronchoscopy procedures (39).

Because some degree of oxygen desaturation occurs in virtually all patients undergoing bronchoscopy with $\mathrm{BAL}$, all patients undergoing BAL should be monitored by EKG and pulse oximetry and should receive supplemental oxygen throughout the entire procedure. Changes in mental status and blood pressure may indicate hypoxemia and should be periodically evaluated as well. If a moderate degree of respiratory impairment is present (hypoxemia or hypercapnea), consideration should be given to intubation for better airway control and possible ventilator management if needed. Following a routine inspection of the tracheobronchial tree, the suction channel is rinsed with sterile saline, the suction trap changed, and the bronchoscope is wedged into a subsegmental bronchus of the middle lobe or the lingula in order to optimize fluid and cell return. When focal chestX-ray abnormalities are present, the FB should be positioned in the affected lobe or bronchopulmonary segment. 
After the bronchoscope is wedged, a $20-50 \mathrm{~mL}$ aliquot of $0.9 \%$ sterile saline at body temperature $\left(37^{\circ} \mathrm{C}\right)$ is gently infused, via a syrringe attached to a three-way stopclock, into the suction port of the bronchoscope. Use of a warmed infusion solution will cause less cough and bronchospasm, and possibly less deterioration of lung function, than will instillations of fluid at room temperature (15). After several seconds, utilizing gentle hand suction, the previously instilled fluid is aspirated into a polyethylene or polycarbonate trap (14). The lavage procedure is repeated until a total of five lavages are performed, utilizing a uniform vol of installate for each lavage. The vol advocated by most investigators ranges from $20-50 \mathrm{~mL}$, and does not appear to be critical as long as individually determined laboratory standards are adhered to.

The first lavage performed is primarily an airway lavage. It may or may not be representative of more distal airways, depending on the amount of large airway disease that is present. It has been recommended that the first sample be discarded or saved to provide a measure of larger airway surface cells and fluid. If a more representative large airway lavage is desired, consideration should be given to use of a double balloon occlusion catheter system (39). The second to the fifth lavage returns, which are enriched for alveolar materials, are combined for purposes of processing. With each lavage the aspirated fluid becomes more dilute, but the ratio of proteins and cells remains relatively constant and thus more total cells are obtained.

The precise method for collecting lavages (and indeed for specimen analysis) requires a methodology dependent on the diagnostic information desired from the BAL fluid. For example, additional lavages are performed if multiple microbial cultures and stains are needed. It is not useful or cost effective to perform every possible lavage test on each BAL, and close communication should occur between the lavaging physician and the technicians responsible for analysis of the BAL fluid contents. The patients should be kept under observation for at least $2 \mathrm{~h}$ following the BAL procedure, during which time they should be evaluated for mental status, recovery from medication, and for stability of cardiopulmonary status and oxygenation.

\section{Complications}

BAL is a fairly safe procedure and there are probably few patients in whom the procedure is contraindicated, although this will in part 
depend on a careful assessment of the benefit to be gained and the precise clinical setting. Relative contraindications to performing BAL that require special precautions be taken include patients who have had a recent meal, patients who are uncooperative or combative, and patients with a recent myocardial infarction or acute respiratory failure. The major complications associated with BAL, such as drug toxicity or hypersensitivity (anaphylaxis), hypoxemia, airway, pleural or parenchymal bleeding, and pneumothorax, are relatively uncommon, and are more often the result of the bronchoscopic and related ancillary procedures such as transbronchial biopsy, rather than the BAL procedure itself (38).

Minor side effects of BAL include coughing (particularly if fluid has leaked proximal to the wedged bronchoscope), fever in 10-30\% of patients (possibly secondary to lavage-induced IL-1release from AMs) (40), a transient or increasing alveolar infiltrate in the lavaged lung segment, brief decrements in pulmonary function parameters, such as vital capacity and forced expiratory vol in one s, and decreases in arterial oxygen tensions. The incidence of minor side effects increase with increasing amounts of infused and/or retained fluid. The fever that most characteristically occurs $4-6 \mathrm{~h}$ after the procedure can be as high as $102^{\circ} \mathrm{C}$ and associated with shaking chills, usually subsides by $24 \mathrm{~h}$. The transient infiltrates on chest $\mathrm{X}$-ray are rapidly absorbed (within hours), and if the infiltrates are persistent, one should suspect disease progression.

\section{Specimen Analysis}

A number of diagnostic options exist, depending on the clinical circumstances present $(12,14,15)$. In most instances, the vol of the BAL fluid return is measured, and the BAL fluid is strained through one or two layers of $4 \times 4$ gauze to remove insoluble mucus components. The filtered pooled fluid is centrifuged (e.g., $5 \mathrm{~min}$ at $200 \mathrm{~g}$ ) and the supernatant is saved for analysis or frozen at $-80^{\circ} \mathrm{C}$ for subsequent study. The residual pellet of cells is then resuspended in a small known vol (e.g., 1-2 mL Hanks' balanced salt solution). The quantification of total cell count in BAL is most accurate when performed on an aliquot of the unspun filtered sample using a hemocytometer. Further cell differential and other specialized cell analyses can then be completed utilizing either cytocentrifuge $(14,15,41)$ or Millipore membrane filtration $(15,42,43)$ techniques. It should be 
recognized that such factors as mucus filtering technique, centrifuge speed, dilution solutions, temperature and vol of lavage solution, cell smear preparation, including use of cytocentrifuge and millipore membranes, staining techniques and methods for reporting cell counts (e.g., including or excluding ciliated/squamous cells) can all affect the differential cell counts $(15,41-46)$. Further information concerning technical preparations are detailed elsewhere (see 14,15). Table 3 provides an approx standard for selected normal BAL fluid constituents in both nonsmokers and smokers.

\section{Cellular Components}

Cell staining is routinely performed using either a WrightGiesma or Diff-Quick stain. Special stains may be employed to further characterize the identity of mononuclear cell populations and to more accurately identify the presence of microorganisms. Using the technique described, BAL using $100 \mathrm{~mL}$ saline in a normal adult should yield approx $40-60 \mathrm{~mL}$ of effluent containing $5-10 \times 10^{6}$ cells (8). In normal adults, $80-95 \%$ of the BAL cells are PMNs, whereas 5-20\% are comprised of lymphocytes and PMNs. Basophils, eosinophils, and mast cells comprise less than $1 \%$ of the total cells.

Special immunofluorescent and immunocytochemical techniques can be utilized to further characterize the phenotypes of BAL cells. Utilizing monoclonal antibodies against antigens present on the cell surface, flow cytometry techniques are replacing the more subjective, time consuming manual methods for detecting and enumerating cell surface and intracellular markers (15). Until recently, the major application of flow cytometry in BAL fluid analysis has been for evaluation of BAL lymphocyte subsets and activation markers in sarcoid and hypersensitivity pneumonitis. However, the technique has considerable potential for investigation of surface and intracellular markers on other types of cells in BAL samples. The number of these markers has recently become available (15).

\section{Noncellular Components}

At present, quantitative studies of the soluble, noncellular constituents of the BAL fluid derived from the respiratory tract epithelial lining fluid have less clinical utility than studies of the cellular components. The expected $40-60 \mathrm{~mL}$ of BAL fluid recovered from a standardized $20 \mathrm{~mL} \mathrm{X} 5$ saline installate should contain approx 1-10 
Table 3

Normal BAL Fluid Constituents*

\begin{tabular}{|c|c|c|c|c|}
\hline $\begin{array}{l}\text { Cell count } \\
10^{6} \text {, totaI }\end{array}$ & $\begin{array}{l}\text { AMS } \\
(8)\end{array}$ & $\begin{array}{l}\text { PNNS } \\
\text { (\%) }\end{array}$ & $\begin{array}{c}\text { Iymphocytes } \\
\left(\frac{\circ}{5}\right)\end{array}$ & $\begin{array}{l}\text { Protein } \\
\text { (mg, total) }\end{array}$ \\
\hline
\end{tabular}

\begin{tabular}{|c|c|c|c|c|}
\hline \multirow[b]{2}{*}{20} & \multicolumn{4}{|c|}{ NON SMOKERS } \\
\hline & $90 \pm 5$ & $1-2$ & $\begin{array}{c}4-14 \\
\left(70-75 \frac{2}{5} \mathrm{~T}-\mathrm{cel} 1 \mathrm{~s}\right)\end{array}$ & $5-15$ \\
\hline \multicolumn{5}{|c|}{ SMOKERS } \\
\hline 80 & $90 \pm 5$ & $2-4$ & $1-5$ & $5-15$ \\
\hline
\end{tabular}

*ADAPTED FROM REFERENCES 10 and 14. TOTAL AMOUNTS OF CONSTITUENTS CAN BE EXPECTED TO VARY WITH AMOUNT OF INSTALLATE VOLUME.

mg of protein $(14,15)$, of which approx one-third is albumin and almost as much is represented by immunoglobulin (15). Larger amounts of protein may be recovered when the permeability of the bronchoalveolar epithelium is increased, as might occur in acute hypersensitivity pneumonitis. More than 100 additional protein species have been detected and quantitated in BAL fluid $(10,15)$. The clinical application of this technology remains uncertain at present. However, with more widespread application of such technologies as radioimmunodiffusion, radioimmunoassays, laser nephelometry, and other sophisticated functional assays, there is a promise that present research activities will be soon translated into useful clinical applications (15).

There are at least two major restrictions that impair standardization of noncellular BAL components. First, the optimal methods required to calculate the concentration of varying species present in the original bronchoalveolar epithelial lining fluid have not been universally agreed upon. Markers such as lavage vol instilled, lavage vol returned, and concentrations of albumin, urea, methylene blue, and potassium have all been utilized to normalize BAL fluid constituents. However, all present significant limitations, as do most methods for concentrating the BAL fluid itself $(15,42)$. Second, the concentration steps needed to measure minuscule amounts of certain constituents of interest (e.g., tumor and viral antigens, mediators, growth factors, lymphokines) often require tedious concentration techniques and attention to detail. As a result, different laboratories report substances retrieved from BAL fluid in different concentra- 
tions and in different units, making comparison of results from various research centers time consuming and prone to error. Given these limitations, expression of concentrations in terms of lavage vol returned and measured without filtration or concentration steps would seem useful.

Utilizing such techniques as two dimension gel electrophoresis, immunodiffusion, and ELISA, hundreds of proteins can be identified in BAL fluid. Table 4 lists some of the components that have been identified in BAL fluids utilizing a variety of specialized technologies.

\section{Dust and Minerals}

With the use of special techniques such as energy-dispersive $\mathrm{X}$-ray microanalysis, BAL has proved to be helpful in detecting inorganic particles that are inhaled during occupational and environmental exposures $(47-51)$. Although BAL mineralogical analysis permits differentiation between exposed and unexposed individuals, it is not yet possible to correlate these BAL findings with pneumoconiosis-related disease activity or severity $(52,53)$. Specialized techniques used to quantify and optimize particle cytological appearance and mineralogical analysis have been reviewed elsewhere $(47-53)$.

\section{Microbial Stains and Cultures}

The use of specialized procedures is essential to process BAL fluid when the presence of infectious agents is suspected. This is the major utility for BAL in immunocompromised patients, and in this setting, it is critical to optimize processing techniques to maximize sensitivity.

For example, in order to increase the yield of Pneumocystis carinii in BAL fluid several technical modifications have been recommended (15). These include increasing the vol of the BAL fluid (more than $200 \mathrm{~mL}$ if the patient is not at risk of respiratory failure), omitting the gauze filtration step $(P$. carinii often found in mucus material filtered out by the gauze), preparation of at least six stained slides with more than $2 \times 10^{5}$ cells each, and sequential staining using Wright-Giemsa or Gram-Weigert stains followed by silver or toluidine blue stains.

Ideally, quality control slides (positive and negative for $P$. carnii) should be processed in the same batch (15). More recently, it has been found that immunofluorescence is as sensitive as the previously 
Table 4

Some Measurable Substances Recovered from BAL Fluid

Albumin
All Serum Globulin Fractions
Specific Immunoglobulins
Gistanine
Frostaglandins
Leukotrienes
Interleukin 1
Interleukin 2
Tumor Mecrosis Factor
Interferons
Bombesin-Iike peptides
Antiproteases
Cathepsins
Collagenases
Elastases
Procoagulant Factors
Plasminogen Activator

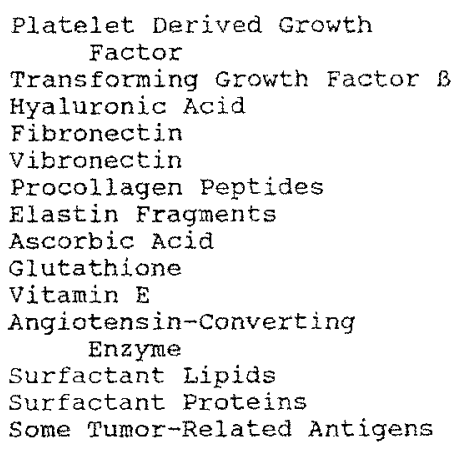

mentioned techniques, but faster and easier to use for detecting $P$. carinii in BAL specimens (54). Multiple BALs may be useful when following these patients.

Direct staining of cytocentrifuge preparations or concentrated smears may reveal mycobacteria, fungi, toxoplasma, cryptosporidia, and other microorganisms (15). Direct detection of microbial antigens in BAL fluid using monoclonal antibodies (e.g., Cryptococci) or fluorescence assays (e.g., Legionella) is possible. To detect cytomegalovirus (CMV) or herpes infection, direct cytological examination may reveal the characteristic viral inclusions. For more sensitive CMV recovery, direct antigen detection by immunofluorescence or immunochemistry can be used (55). In addition, cultures and DNAprobe analysis are finding increasing application in the detection of virus $(56,57)$. Similar techniques, as well as reverse transcriptase assay and enzyme immunoassays, have been used to detect Human Immunodeficiency Virus and its p24 antigen in BAL fluid of AIDS patients (58).

Using special precautions to reduce oropharyngeal contamination, quantitative culturing of BAL fluid can be used to differentiate bacterial contamination and colonization from clinically significant lower respiratory tract infections (59-62). BAL fluid cultures from patients with clinically active bacterial pneumonias typically have more than $10^{5}$ colony-forming units per $\mathrm{mL}$ of BAL fluid. Gram stain of cytocentrifuged specimens show a high degree of correlation with the BAL fluid cultures. It has been suggested that quantitative BAL fluid cultures will become the method of choice for investigating pulmonary infiltrates compatible with bacterial pneumonia in the immunocompromised host (15). 


\section{Cancer Detection}

FB guided endobronchial biopsy, brushings, needle aspirations, and washings of airway mucosal surfaces are the methods of choice in lung tumor diagnosis. Although BAL cytology, when combined with such specialized techniques as flow cytometric DNA analysis (63) and tumor or tumor marker antigen detection (64), would appear to have the potential to increase the diagnostic yield of the standard bronchoscopic procedures, BAL has yet to be shown to play an important role in the diagnosis of most lung tumors. This situation may change as detection techniques for specialized tumor markers become more sensitive and more widely available. BAL has found some application in the localization of occult lung tumor (pap smear positive but $\mathrm{X}$-ray and endoscopic exam unrevealing) and in the diagnosis of peripheral tumors, including alveolar cell carcinoma. BAL appears to be particularly helpful in lymphoma that involves the lung (65), and has been advocated as the diagnostic procedure of choice to confirm the diagnosis of lymphangitic carcinomatosis (65a).

\section{Specific Disease Categories}

As implied in Table 1, analysis of the content of BAL fluid cannot by itself be expected to provide enough data to make a specific diagnosis in most noninfectious disease categories. However, in conjunction with the history, pulmonary function data, and X-ray diagnostic information, BAL profiles can contribute to the diagnosis and evaluation of disease activity in a number of lung disorders. In a minority, the BAL findings may, in fact, yield the diagnosis. Results of BAL fluid examination from some of the more common specific lung diseases in which this procedure has potential significant clinical utility, are as follows.

\section{Sarcoidosis}

Sarcoid is characterized by a mononuclear cell alveolitis that precedes and coexists with the presence of noncaseating granulomas $(8,9)$. In this disease, the activated T-lymphocyte population seems to play a fundamental role in modulating the granuloma formation within the lung parenchyma, the characteristic sarcoid lesion.

Presumably, this is a function of synthesis and liberation of such products as lymphokines and growth factors inducing AM, B-lymphocyte, and fibroblast activation (14,66-70). In this regard, it has been 
suggested that the lymphocytic component of BAL fluid can provide information regarding the intensity of sarcoid alveolitis, with lavage T-lymphocytes $>28 \%$ representing "high-intensity" alveolitis and 15-28\% representing "low-intensity" alveolitis. If correct, this might provide important predictive information on which therapeutic decisions could be based $(8,71-73)$. Others have maintained that this determination is devoid of any predictive value, particularly when evaluation is undertaken during the early stages of the disease $(74,75)$.

One group has found the helper/suppressor T-lymphocyte cell ratio to be more helpful than the absolute lymphocyte percentage in predicting the clinical course in patients with sarcoid. A normal helper/suppressor ratio (approx 1.8/1) was predictive of a stable clinical course, whereas an elevated ratio (as high as 10-20/1) was associated with clinical deterioration during a followup period of several years (71). Other researchers have not found this ratio to be predictive of the eventual clinical course of the disease, although they do report that decreases in helper/suppressor $T$-cell ratios precede, or are accompanied, by a clinical improvement (76).

It has been recently suggested that the maximally activated helper T-cell epitome subpopulations within the alveolar helper $\mathrm{T}$ cell (CD4+) population may play a significant role in modulating local immune responses in the lung. Increased numbers of a subgroup of the CD4+ cells within BAL fluid from patients with sarcoid would, therefore, imply greater pathogenicity and increased clinical relevance than determinations of the total helper T-cell alone (72,73). For example, CD4+ TQ1- cells, a minor component of the CD4+ population, correlate better with BAL immunoglobulin levels and disease activity than the overall total CD4+ cell population in sarcoidosis (72). These CD4+TQ1-T-lymphocytes are the type of T-cells that can induce maximal B-cell immunoglobulin secretion. Elevation of this cell population may explain the marked increase in immunoglobulin levels in BAL fluid of patients with sarcoidosis $(77,78)$.

A variety of other markers of immune and interstitial tissue metabolic activity have been reported in BAL fluids recovered from sarcoid patients. These include activated alveolar macrophages (AMs) $(67,68,79-81)$, matrix constituents, such as fibronectin (82) and procollagen III peptide (83), proteolytic enzymes such as collagenase and elastase (84), and various cytokinins, such as LL-1, L-2, TNF, and interferon $(67,79,81,85,86)$. Further studies may eventually help identify important operative mechanisms in the patho- 
genesis of the disease. However, at the present time, the clinical implications of these findings remain unclear. In evaluating BAL fluid derived from sarcoid patients, the clinician should recognize that the alveolitis and granulomatous lesions may not be evenly distributed throughout the pulmonary parenchyma, and this may cause some variation in the BAL cell counts from different regions of the lung (12).

There is, as yet, no overwhelming consensus on the precise usefulness of BAL cell counts and cell phenotypes in the clinical management of patients with sarcoidosis. The documentation of a lymphocytic alveolitis is undoubtedly helpful in the clinical diagnosis of sarcoid, but cannot be used alone to make the diagnosis, assess disease activity, or guide treatment strategy.

The increase in helper/suppressor T-lymphocyte ratio is of benefit in distinguishing sarcoid from other forms of granulomatous lung diseases such as hypersensitivity pneumonitis. It is speculated that information obtained from assays of cell function such as immunofluorescent staining and flow cytometry, by identifying particularly active subpopulations of lymphocytes and alveolar macrophages, may eventually aid the clinician in formulating patient management strategies (12).

\section{Hypersensitivity Pneumonitis}

Hypersensitivity pneumonitis represents a localized immunologic reaction in the lung of sensitized individuals in response to pulmonary inhaled antigens. The characteristic BAL finding in these individuals is a lymphocytic alveolitis, but unlike sarcoid, there is an increased number of suppressor T-lymphocytes $(87,88)$. Such a finding should trigger an intensified search for potential immunogens in the environment of the patient. As increased numbers of PMNs are present in the BAL fluid early after experimental antigen inhalation challenge (89), the timing of the antigen exposure may represent a significant variable. Scientific evidence of the utility of BAL in assessing the prognosis of the disorder has not been forthcoming (14). Many asymptomatic dairy farmers with positive precipitins to antigens believed to play a role in the etiology of Farmer's Lung have an alveolar lymphocy tosis lasting as long as 5-6 yr. This suggests that BAL fluid lymphocytosis per se does not predict the development or severity of clinical disease $(31,90)$. This has some important implications in that therapeutic proteins may soon be administered via the aerosol route (91), and if this method of pharmacotherapeutics be- 
comes prevalent, problems of interpreting inereased quantities of immune effectors cells such as lymphocytes in BAL fluids will become even more clinically relevant.

\section{Idiopathic Pumonary Fibrosis (IPF; Fibrosing Alveolitis)}

As this represents the most common form of diffuse interstitial inflammation and fibrosis, it is no surprise that clinicians and investigators have centered their attention on the potential usefulness of BAL in this disease. This is particularly so as IPF has such a variable prognosis, natural history, and response to corticosteroid and cytotoxic agent therapy. As in the case of sarcoidosis, interest has focused on finding specific markers in BAL fluid that would predict prognosis and aid in decisions affecting patient management. As in the case for sarcoid, no clear consensus has emerged. Although PMNs have been long recognized as the characteristic BAL cell type present from patients with active IPF, there is no unity of opinion as to the precise role the PMN plays in either the clinical management or the pathogenesis of IPF.

The percent of PMNs within BAL fluids derived from different lung regions in IPF patients may differ significantly (12). Although the chest $X$-ray pattern in IPF may appear uniform, the pathology is quite variable from one area to another, even within the same lobe (92). Thus, it is not surprising that cell types and numbers within BAL from IPF patients may misjudge the intensity of overall disease activity (12).

An increased number of lymphocytes in the BAL fluid recovered from patients with IPF may be predictive of an improved response to corticosteroids or cytotoxic therapeutic agents (92). The phenotype of the dominant lymphocytes in IPF are unlike those present in sarcoid (94). Others have found that the presence of eosinophils correlates with progressive deterioration of pulmonary function $(93,95)$. An increased number of mast cells has been found in BAL fluids derived from patients with active IPF (12). The fact that AMs in patients with IPF have been found to produce increased levels of platelet-derived growth factor (PDGF) compared with AMs recovered from normal subjects suggests that cytokinins and/or growth factors may play an important role in the pathogenesis of this disorder (96). For example, PDGE stimulates resting cells to enter the cell cycle and divide. High localized levels of PDGF could stimulate mesenchymal cells to proliferate at an inappropriately high rate, thus contributing to the increase in interstitial connective tissue constituents that characterize 
IPF. The recently confirmed finding that the fibrosis, in chronic pulmonary fibrosis, results mainly from organization of an inflammatory exudate within airspaces (just as it does after acute lung injury), should stimulate considerable ongoing research interest in the further identification and assay technology of BAL fluid "markers" of intra-alveolar fibrogenic processes (99a). These "markers" will predictively include not only the soluble products of cells which modulate fibroblast function, but should include information present in the various matrix components themselves.

\section{Lung Interstitial Disease Associated with Connective Tissue Disease}

The relationship between clinical activity of disease, pulmonary function tests, chest X-rays, pathology, and BAL findings in the various types of connective tissue diseases that can involve the lung remain to be clarified. The lung inflammatory processes, and the prognosis and response to therapy in patients with connective tissue disease and associated illness, appear to be quite similar to IPF (97, 98). Most patients with connective tissue disease have a predominantly neutrophilic alveolitis $(97,99)$. As with patients with IPF, lymphocytes in the BAL fluid may predict a positive response to therapy, whereas the presence of eosinophils appears to. portend a less favorable prognosis (14).

Patients with connective tissue disorders who are free of pulmonary symptoms, pulmonary function abnormalities, and chest X-ray abnormalities may have "subclinical" pulmonary involvement, as reflected by a high incidence of abnormal BAL findings (32-34). A PMN alveolitis, with or without an increased percentage of lymphocytes, has been reported in patients with rheumatoid arthritis, scleroderma, mixed connective tissue disease, and dermatomyositis (32-34). AM activation has also been demonstrated in many of these patients (99). By contrast, a lymphocytic alveolitis is found in patients with Sjogren syndrome, with or without another coexisting connective tissue disease $(99,100)$. BAL abnormalities are more common in patients with active and severe extrapulmonary disease. Although it has been observed that patients with connective tissue disease and concurrent subclinical PMN alveolitis are at a greater risk for progression of their disease, it is not yet clear how this knowledge should be used for management decision analysis. 


\section{Pneumoconiosis and Occupational Lung Disease}

The potential usefulness of BAI in evaluating or treating individuals with different types of inhalation exposure is being increasingly recognized. As in patients with collagen vascular disease, the BAL fluid of patients with asbestosis has been shown to be quite similar to that of patients with IPF, except that asbestosis bodies may be found (101). However, the presence of asbestos bodies within BAL fluid does not necessarily reflect concurrent active asbestosis-related disease $(14,102)$, nor does the extent of abnormalities within BAL fluid necessarily reflect the degree of pulmonary function abnormality or X-ray severity present $(53,103)$. As has been reported in collagen vascular diseases (33), "subclinical" alveolitis may occur in asymptomatic asbestos exposed workers, some of whom will develop asbestosis $(101,104)$.

Abnormal BAL fluid contents have also been noted in silicaexposed workers with or without $\mathrm{X}$-ray abnormalities $(47,51,104)$. In studies of these patients, it is helpful to document polarizing particles in the lavaged AMs. Patients with silicosis may also have increased concentrations of lymphocytes in BAL fluid (47). Patients with chronic interstitial disease secondary to inhaled beryllium metal dusts, berylliurn oxide, or beryllium salts, as in patients with sarcoid, have an increase in helper T-lymphocytes in BAL fluid $(11,14)$. These T-lymphocytes proliferate when stimulated with soluble beryllium salts, distinguishing them from lymphocytes derived from sarcoidosis patients $(11,12,14)$.

Analysis of particulate material in BAL phagocytes by means of energy dispersive X-ray spectroscopy represents one approach to the quantitative evaluation of lung exposure to such particulate materials as hard metal, fumes, and particulate dust $(15,51)$. Therapeutic lung lavage may reduce the number of toxic particles within the lung after acute exposure, and represents a method to reduce inhaled toxic particulate-induced damage to the lung.

\section{Histiocytosis X (Eosinophilic Granuloma)}

The finding in BAL fluid of the typical histiocytosis $\mathrm{X}$ macrophage, possibly representing a malignant transformation of the lung Langerhans cell, has occasionally been reported in this disease (105). Otherwise, the number and differential counts of BAL fluid cells are unremarkable. 


\section{Drug-"Induced Lung Disease}

An increasing number of patients are receiving anti-inflammatory and other cytoxic or immune modulating drugs that can cause acute, subacute, or chronic lung injury (106). As these agents can injure the lung either by direct toxic mechanisms or by hypersensitivity reactions, the BAL fluid cell differential is not diagnostic, although the presence of large numbers of eosinophils suggests an allergic drug reaction. Epithelial cell atypia, including nuclear enlargement, hyperchromasia and increased cytoplasmic staining density frequently accompanies the administration of antineoplastic agents. However, the presence of these cells within BAL fluids may not be specific for quantitating the degree of drug-induced lung disease that may be present.

\section{Alveolar Proteinosis}

BAL fluid often can provide important diagnostic information in patients with this disease. The most characteristic abnormalities include an opaque or milky lavage return, and Periodic-Acid-Schiff staining of the proteinaceous material with a lack of Alcian Blue staining (107).

\section{Eosinophilic Pneumonia}

BAL fluid in these patients reveals a marked increase in eosinophils that can be reversed with steroid therapy (108).

\section{Alveolar Hemorrhage}

BAL fluid containing large amounts of red blood cells or alveolar macrophages with intracellular hemosiderin should suggest the possibility of accult pulmonary hemorrhage $(14,19,109)$. However, it should be remembered that hemorrhage can occur secondary to bronchoscopy-associated trauma or infection and that hemosiderin-laden macrophages can be seen in a variety of other lung diseases $(11,14)$.

\section{Bronchiolitis Obliterans}

The utility of BAL for evaluating the inflammatory response present at the level of the bronchiolus in patients with bronchiolitis obliterans has been recognized (110). Specifically, these patients were found to have large percentages of PMNs in their BALs (53 \pm $13 \%$ ), even when compared to cigaret smokers with chronic bronchitis 
(Table 3). More recently, it has been found that BAL findings could be related to open lung biopsy findings, and that $\mathrm{BAL}$ from these patients contained products of neutrophil oxidative and proteolytic activities (myeloperoxidase and collagenase). Further, patients who benefited from administration of corticosteroids (steroid "responders") showed significant concomitant reductions in their BAL PMN counts (111).

\section{Uthily in Immunocompromised Hosts Including ADS}

BAL is the major diagnostic intervention in the evaluation of localized or diffuse air space disease in which viral, protozoal, fungal, mycobacterial or Legionella infections are suspected. BAL also aids the clinician in evaluating the possible presence of neoplasia, alveolar hemorrhage, nonspecific pneumonitis, and drug or radiation-induced lung toxicity. With the use of newer procedures to minimize upper airway contamination (59), and using quantitative techniques (60$62)$, BAL can even be useful in the diagnosis of bacterial pneumonia $(27,28,30,112)$.

The value of BAL in the identification of the opportunistic organisms that afflict AIDS patients is widely acknowledged $(21,113,114)$. Some of these patients, particularly at early stages, may exhibit BAL lymphocytosis, perhaps reflecting a primary HIV pneumonitis (115). Others may exhibit neutrophilia suggesting a more severe form of lung injury and a poor prognosis (116). Still others may exhibit an eosinophilia (117). BAL fluid from AIDS patients has a higher concentration of $\operatorname{IgG}$ levels than levels of IgG in BAL fluid from healthy individuals (118), again reflecting very significant alterations in cellular and humoral immunity in the alveolar compartment of the lungs of these patients.

Analysis of BAL fluid in patients who have received heart, lung, or heart-lung transplants, bone marrow, liver, or kidney transplants is playing an increasingly prominent role in monitoring for the presence of infection and in defining the presence of immune-mediated pneumonitis (119-122). Opportunistic infections of the lung, especially with CMV and Herpes Simplex type 1 virus, are major causes of morbidity and death in patients with heart-lung and single lung transplants. The diagnostic problem is further compounded by the fact that viral serology or BAL culture studies are seriously flawed in this group of patients, because of a high incidence of tracheobronchial colonization with CMV, even in cases of rejection pneumonitis. To 
date, no quantitative viral culture techniques have been developed that would help distinguish viral colonization from infection. Thus, FB tissue biopsies are usually required to distinguish viral pneumonitis from rejection.

In immunocompromised patients, especially in cases where immunomediated lung pneumonitis is suspected (e.g., lung and bone marrow transplantation), careful analysis and phenotyping of BAL fluid cells may eventually prove to be helpful in distinguishing between opportunistic infections (especially viral), drug reactions, and treated and untreated rejection states. For example, in untreated rejection reactions BAL fluid lymphocytosis with greater expansion of the CD8 T-lymphocyte population pool is present, when compared to BAL fluid from patients with viral infection (120). There may also be a greater expression of IL-2 receptors on lymphocytes derived from BALs of patients undergoing rejection phenomenae. In contrast, in bone marrow associated pneumonitis owing to infectious or noninfectious causes, BAL lymphocytosis with substantial numbers of cells expressing none of the B- or T-cell antigens ("null" cells) is found (121).

\section{Research Considerations}

The analysis of cells, proteins, enzymes, inflammatory mediators, and other cellular and matrix component products from BAL fluids has provided a new and significant investigative technique for pulmonary research, in both experinental animals, models of lung injury, and in naturally occurring lung disease. Such studies have helped to elucidate pathogenetic mechanisms in several pulmonary diseases, even though BAL is not presently helpful in the diagnosis or clinical management of the patient (Table 1). A few examples are given below.

\section{Cigaret-Smoke Disease Protease-Antiprotease and Oxidant-Antioxidant Balance}

Descriptions of abnormal BAL cellular contents from cigaret smokers (using endobronchial catheter techniques) $(3,4)$ antedate the widespread use of the fiberoptic bronchoscope which occurred in the early 1970 s. In the 1980 s, smoking-induced changes in the quantity of cells, proteins, and enzymes recovered by BAL were extensively documented, and at least 20 different abnormalities described (10). 
The major findings include large increases in the number of AMs that are larger than normal and are usually in an activated state (12). These AMs contain more intracellular granules and lysosomal enzymes, including proteases, than normal cells $(3,4,6,10,123-125)$. However, they express less Ia surface antigen than do AMs from nonsmokers ( $40-50 \%$ vs $80-90 \%$ ) (12). BAL fluid itself may contain more protease-activity in cigaret smokers $(12,124)$. However, there continues to be some regarding the precise temporal (immediately after smoking; hours after smoking) and geographic (airways; bronchiolaralveolar regions) protease and antiprotease proteins present in the respiratory tract passages of cigaret smokers (12).

The impact of the gaseous phase and particulate phase constituents of cigaret smoke on both lung epithelial lining fluid protease antiprotease and oxidant-antioxidant balances is clearly an important issue regarding to the pathogenesis of cigaret smoke-related airway and parenchymal injury $(12,126)$. Whereas it is clear that cigaret smoke is capable of oxidative inactivation of alpha-1antiprotease (12) (the predominant protease present in lung lining fluid), it is also recognized that the lung epithelial lining fluid contains large amounts of antioxidant substances including glutathione and ascorbate $(127,128)$. Ascorbate is extremely efficient at protecting plasma from peroxidation (129). The role of cigaret smoke on these lung protective antioxidant systems is yet to be fully evaluated.

The recent demonstration that BAL antiproteases (91) and BAL antioxidant substances (130) can be clinically determined and augmented by aerosol administration, illustrates a potential clinical application of this research technology as it relates to cigaret smoke toxicity. Likewise, the recent finding that increased levels of bombesin-like peptides are present in the lower respiratory tract fluid of asymptomatic cigaret smokers suggests an increased proliferation of neuroendrocrine cells in bronchial epithelium, implying a potential link to the eventual development of tumors of this cell line in cigaret smokers (oat cell, e.g., small cell carcinoma) or, alternatively, it is possible that the bombesin-related peptides stimulate proliferation of other bronchial epithelial cell lines, mimicking the role of tumor promoting factors in all forms of lung carcinogenesis (130a).

\section{Adull Respiratory Distress Syndrome (ARDS)}

Sepsis, shock, massive trauma, aspiration, lung infection, and inhalation of smoke or noxious chemicals are among the most com- 
mon clinical disorders that can incite this diffuse acute lung injury termed ARDS. Regardless of the specific etiology, endothelial and epithelial sides of the blood-brain barrier are damaged, and concomitant with this problem, abnormalities have been reported in BAL fluid that presumably reflect the various stages of acute lung parenchymal damage. Analysis of inflammatory-immune effector cells, enzymes, oxidants, and other mediators have yielded considerable insight into the pathogenic events occurring in the disturbed lung tissue.

Studies to date suggest that PMN activation and infiltration into the lung, proteases including elastase, lymphokines, chemotactic factors, and oxidative stress may all play a role in the pathogenesis of ARDS $(131,132)$. Thus far, such information obtained from BAL in ARDS patients has helped to characterize the inflammatory-immune response, but has not been used routinely to diagnose or plan patient management. However, many ARDS patients die as a result of pulmonary infections occurring late in their disease (133), and BAL fluid analysis may help to assess the significance of positive sputum cultures. It may be difficult to distinguish between tracheobronchial colonization and true nosocomial pneumonia in the patient with the diffuse alveolar infiltrates characteristic of ARDS.

\section{Asthma}

BAL has recently emerged as a safe and well-tolerated procedure for the investigation of the immunopathology of mild asthma (10, 134-135). As asthmatic reactions are believed to occur on respiratory tract airway surfaces, access to the respiratory tract surface cells and fluid might be expected to be particularly useful in this disease. Such access, provided by BAL, aids in the evaluation of the role of various mediators in acute and late phase asthmatic reactions, in chronic asthma, and in various models of asthma induced by inhalation challenge with allergens, drugs, and air pollutants (10,134-139). Studies to date have demonstrated increased total cell counts, increased numbers of metachromatic cells and eosinophils, increased concentrations of arachidonic acid metabolites, as well as increased levels of mast cell tryptase and histamine in BAL fluid from both naturally occurring and experimentally induced asthmatic subjects (135-140). Such studies utilizing BALs from asthmatics have also revealed an important role for AMs in the pathogenesis of asthma (141). 


\section{Acute Experimental Lung Injury}

Cellular and biochemical analysis of $\mathrm{BAL}$ is being increasingly used as an index of lung inflammation and toxicity (142-147). Total lavage cell counts, cell differential, cell morphology, total protein, albumin, globulins, enzymes such as $\mathrm{LDH}$, and various plasma injectates (such as radioactive albumin) have been used to assess alveolar capillary "permeability," and have been helpful in this regard. With the increasing recognization that most forms of both acute lung injury and chronic lung fibrosis result primarily from inflammation and organization of airspaces (99a), it can be expected that BAL will join pulmonary function testing as an important research diagnostic tool in quantitative investigations of lung injury and repair mechanisms and the efficacy of drug therapy in disease.

\section{SUMMARY}

The technique of BAL performed through the fiberoptic bronchoscope has, in two decades, provided clinicians and researchers with the ability to safely sample the inflammatory-immune cell milieu of the human lung. Standardized BAL and processing of the lavage constituents provides assistance in determining the optimal care of patients with a variety of lung diseases, and renders diagnosis in selected cases. It has become indispensable in the diagnosis of pulmonary infiltrates in immunocompromised patients, and plays an important role in improving clinical management. Finally, it continues to yield an ever increasing amount of data for the researchers studying the mechanisms and pathogenesis oflung disease. It is likely that BAL will become an even more valuable tool with increasing relevance to the practice of chest medicine in the 1990 s.

\section{References}

1. Kylstra, J. A. (1958), Acta Physiol. Pharm. Neerl. 7, 163-221.

2. DeBoer, J. (1963), Acta Physiol. Pharm. Neerl. 12,345-355.

3. Finley, T. N. and Ladman, A. J. (1972), N. Engl. J. Med. 286, 223-227.

4. Finley, T. N, Swenson, E. W., Curran, W. S., et al. (1967), Ann.Intern. Med. $66,651-658$.

5. Ramirez, R. J. and Halprin, G. (1973), Bol. Assoc. Med. PR 65, 183-187.

6. Reynolds, H. Y. and Newball, H. H. (1974), J. Lab. Clin. Med. 84, 559-573. 
7. Hunninghake, G. W., Gadek, J. E., Kawanami, O., et al. (1979), Am. J. Pathol. 97, 149-206.

8. Crystal, R. G., Roberts, W. C., Hunninghake, G. W., et al. (1981), Ann. Intern. Med. 94, 73-94.

9. Crystal, R. G., Bitterman, P. B., Rennard, S. I, et al. (1984), N. Engl. J. Med. 310, 154-166, 235-244.

10. Reynolds, H. Y. and Chretien, J. (1984), Disease-A-Month \$0, 1-103.

11. Daniele, R. P., Elias, J. A., Epstein, P. E., et al. (1984), Ann. Intern. Med. 102,93-108.

12. Crystal, R. G., Reynolds, H. Y., and Kalica, A. R. (1986), Chest \$0, 122-131.

13. Reynolds, H. Y. (1987), Am. Rev. Respir. Dis. 135, 250-263.

14. Helmers, R. A. and Hunninghake, G. W. (1989), Biopsy Techniques in Pulmonary Disorders, (Wang, K. P., ed., Raven Press, Ltd., New York, pp. 15104.

15. Report of the European Society of Pneumology Task Group on BAL. Eur. Respir. J. 2, 561-585.

16. Hunninghake, G. W., Kawanami, O., Ferrans, I. J., et al. (1981), Am. Rev. Respir. Dis. 123, 401-407.

17. Haslam, P. L., Turton, G. W. G., Heard, B., et al. (1980), Thorax 35, 9-18.

18. Paradis, I. L., Dauber, J. H., and Rabin, B. S. (1986), Am. Rev. Respir. Dis. $133,855-860$.

19. Stover, D. E., Zaman, M. B., Hajdu, S.I., et al. (1984), Ann.Intern. Med. 101, $1-7$.

20. Stover, D. E., White, D. A., Romano, P. A., et al. (1984), Am. Reu. Respir. Dis. 130,659-662.

21. Broaddus, C., Dake, M. D., Stulbarg, M. S., et al. (1985), Ann. Intern. Med. $102,747-752$.

22. Cordonnier, C., Bernaudin, J. F., Fleury, J., et al. (1985), Am. Rev. Respir. Dis. 132, 1118-1123.

23. Watters, L. C., Schwarz, M. I., Cherniack, R. M., et al. (1987), Am. Rev. Respir. Dis. 135, 696-704.

24. Stoller, J. K., Rankin, J. A, and Reynolds, H. Y. (1987), Chest 92, 839-843.

25. O'Donnell K., Keogh, B., Cantin, A., et al. (1987), Am. Rev. Respir. Dis. 136, 288-292.

26. Turner-Warwick, M. and Haslam, P. L. (1987), Am. Rev. Respir. Dis. 135, $26-34$.

27. Martin, W. J., Smith, T. F., Sanderson, D. R., et al. (1987), Mayo Clin. Proc. $62,549-557$.

28. Xaubet, A., Torres, A., Marco, F., et al (1989), Chest $95,130-135$.

29. de Gracia, J., Curull, V., Vidal, R., et al. (1988), Chest 93, 329-332.

30. Torres, A., De La Bellacasa, J. P., Xaubet, A., et al. (1989), Am. Rev. Respir. Dis. $140,306-310$.

31. Gariepy, L., Cormier, Y., Laviolette, M., et al. (1989), Am. Rev. Respir. Dis. 140, 1386-1389.

32. Gardia, J. G. N., Parhami, N., Killam, D., et al. (1986), Am. Rev. Respir. Dis. $133,450-454$.

33. Wallaert, B., Hatron, P., Grosbois, J., et al. (1986), Am. Rev. Respir. Dis. $133,574-580$.

34. Martinot, J. B., Wallaert, B., Hatron, P. Y., et al. (1989), Eur. Respir. J. 2, 437-443. 
35. Bergen, C. J. and Muller, N. L. (1987), Am. J. Radiol. 148, 9-15.

36. Klein, J. and Gmsu G. (1989), Prog. Clin. Rad. 24, 805-812.

37. Rankin, J. A., Naegel, G. P., and Reynolds, H. Y. (1986), Am. Rev. Respir. Dis. 133, 186-190.

38. Suratt, P. M., Smiddy, J. F., and Gruber, B. (1976), Chest $69,747-751$.

39. Zehr, B. B., Casale, T. B., Wood, D., et al. (1989), Chest 95, 1059-1063.

40. Huang, Z. and Eden, E. (1989) Am. Rev. Respir. Dis. 139, A575.

41. Willcox, M., Kervitsky, A., Watters, L. C., etal. (1988), Am. Rev. Respir. Dis. $138,74-80$.

42. Lam, S., LeRiche, J. C., and Kijek, K (1985) Chest 87, 740-742.

43. Thompson, A. B., Robbins, R. A., Ghafouri, M. A, et al. (1989), Acta Cytol. $33,544-549$.

44. Linder, J., Radio, S. J., Robbins, R. A., et al. (1987), Acta Cytol. 31, 796-801.

45. Linder, J., Vaughan, W. P., Armitage, J. O., et al. (1987), Am. J. Clin. Pathol. 88, 421-428.

46. Kelly, C. A., Ward, C., Bird, G., et al. (1989), Resp. Med. 83, 107-110.

47. Christman, J. W., Emerson, R. J., Graham, W. G., et al. (1985) Am. Rev. Respir. Dis. 132,393-399.

48. Johnson, N. F., Haslam, P. L., Dewar, A., et al. (1986), Arch. Environ. Health 41, 133-144.

49. Maier, E. A., Dietemann-Molard, A., Rastegar, F., et al. (1987), Clin. Chem. 33, 2234-2239.

50. De Vuyst, P., Dumortier, P., Leophonte, P., et al.(1987), Eur. J. Respir. Dis. $70,150-156$.

51. Nugent, K. M., Dodson, R. F., Idell, S., et al. (1989), Am. Rev. Respir. Dis. $140,1438-1441$.

52. De Vuyst P., Dumortier, P., Moulin, E., et al. (1987), Am. Rev. Respir. Dis. $136,1219-1224$.

53. Xaubet, A., Rodgiquez-Roisin, R., Bombi, J. A., et al. (1986), Am. Rev. Respir. Dis. 133, 848-854.

54. Gill, V.J., Evans, G., Stock, F., et al. (1987), J. Clin. Microbiol. 25, 18371840.

55. Shuster, E. A., Beneke, J. S., Tegtmeier, G. E., et al. (1985), Mayo Clin. Proc. 60, 577-585.

56. Brigati, D. J., Meyerson, D., Leary, J. J., et al. (1983), Virology 126,32-50.

57. Hilborne, L. H., Neilberg, R. K, Cheng, L., et al. (1987), Am. Clin. Pathol. 87, 86-89.

58. Linnemann, C. C., Baughman, R. P., Frame, R. T., et al. (1989), Chest 96, 64-67.

59. Pang, J. A., Cheng, A. F., Chan, H. S., et al. (1989), Lung 267, 261-267.

60. Kahn, F. W. and Jones, J. M. (1987), J. Infect. Dis. 155, 862-869.

61. Thorpe, J.E., Baughman, R. P., Frame P.F., etal. (1987), J.Infect. Dis. 105, $855-861$.

62. Kirkpatrick, M. B. and Bass, J. B. (1989), Am. Rev. Respir. Dis. 139, 546548.

63. Yoss, E. B., Berd, D., Cohn, J. R., et al. (1989), Chest 96, 54-59.

64. Goldstein, N., Lippmann, M. L., Goldberg, S. K, et al. (1985), Rev. Respir. Dis. 132,60-64.

65. Wisecarver, J., Ness, N. J., Rennard, S. I., et al. (1989), Acta Cytol. 33, $527-532$. 
65a. Levy, H., Horak, D. A., Lewis, M. I. (1988), Chest 94, 1028-1030.

66. Hunninghake, G.W., Garrett, K. C., Richerson, H. B, et al. (1984), Am. Rev. Respir. Dis. 130, 476-496.

67. Moseley, P.L., Hemken, C., Monick, M., et al. (1986), Chest 89, 657-662.

68. Gerli, R., Darwish, S., Broccucci, L., et al. (1989), Chest 95, 811-816.

69. Muller-Quernheim, J., Kronke, M., Strausz, J., et al. (1989), Am. Rev. Respir. Dis. 140,82-88.

70. Spurzem, J. R., Saltini, C., Kirby, M., et al. (1989), Am. Rev. Respir. Dis. $140,89-94$.

71. Costabel, U., Bross, K. J., Guzman, J., et al. (1986), Ann (NY), Sci. 465, 418-426.

72. Gerli, R., Darwish, S., Broccucci, L., et al. (1989), Chest 95, 811-816.

73. Ainslie, G. M., Poulter, L. W., and DuBois, R. M. (1989), Thorax 44, 501-509.

74. Israel-Biet, D., Venet, A., and Chretien, J. (1986), Ann. NY Acad. Sci. 465, 395-406.

75. Buchalter, S., App, W., Jackson, L., et al. (1986), Ann. NY Acad. Sci. 465, 678-684.

76. Ceuppens, J. L., Lacquet, L. M., Marien, G., et al. (1984), Am. Rev. Respir. Dis. 129,563-568.

77. Bauer, W., Gorny, M. K., Baumann, H. R., et al.(1985),Am.Rev. Respir. Dis. 132, 1060-1065.

78. Spatafora, M., Mirabella, A., Rossi, G. A., et al. (1988), Eur. Respir. J. 1, 505-509.

79. Robinson, B. W., McLemore, L., and Crystal, R. G. (1985), J. Clin. Invest. 75, 1488-1495.

80. Sibille, Y., Naegel, G.P., Merrill, W. W., et al. (1987), J.Lab. Clin. Med. 110, 624-633.

81. Spatafora, M., Merendino, A., Chiappara, G., et al. (1989), Chest 96, 542 549.

82. O'Connor, C., Odlum, C., VanBreda, A., et al. (1988), Thorax 43, 393-400.

83. Bjermer, L., Thunell, M., and Hallgren, R. (1986), Lab. Invest. 55, 654-656.

84. Mordelet-Dambrine, M., Lafuma, C., Stanislas-Leguern, G., et al. (1988), Eur. Respir. J. 1,748-757.

85. Hunninghake, G. W. (1984), Am. Rev. Respir. Dis. 129, 569-572.

86. Lawrence, E. C., Brousseau, P., Berger, M. B., et al. (1988), Am. Rev. Respir. Dis. 137,759-764.

87. Leatherman, J. W., Michael, A. F., Schwartz, B. A., et al. (1984), Ann. Intern. Med. 100,390-392.

88. Semenzato, G., Trentin, L., Zambello, R., et al. (1988), Am. Rev. Respir. Dis. $137,70-74$.

89. Fournier, E., Tonnel, A. B., Gossett, P., et al. (1985), Chest 88, 563-566.

90. Cormier, Y., Belanger, J., and Laviolette, M. (1986), Am. Rev, Respir. Dis. $133,843-847$.

91. Hubbard, R. C., Brantly, M. L., Sellers, S. E., et al. (1989), Ann. Intern. Med. 111, 206-212.

92. Winterbauer, R. H., Hammer, S. P., Hallman, K. O., et al. (1978), Am. J. Med. $65,661-672$.

93. Wallaert, B., Hatron, P. Y., Grosbois, J. M., and et al. (1986), Am. Rev. Respir. Dis $139,574-580$. 
94. Paradis, I. L., Dauber, J. H., and Rabin, B. S. (1986), Am. Rev. Respir. Dis. $133,855-860$.

95. Peterson, M. W., Monick, M., and Hunninghake, G. W. (1986) Am. Rev. Respir. Dis. 133(4, Part 2),A145 (abstract).

96. Martinet, Y., Rom, W. N., Grotendorst, G. R., et al. (1987), N. Engl. J. Med. $317,202-209$.

97. Hunninghake, G.W. and Gadek, J. E. (1981,1982), Clin. Immunol. Rev. 1, $337-374$.

98. Garcia, J. G. N., Parhami, N., Killam, D., et al. (1986), Am. Rev. Respir. Dis. $133,450-454$.

99. Wallaert, B., Bart, F., Aerts, C., et al. (1988), Thorax 43, 24-30.

99a. Kuhn, C., Boldt, J., King, T. E., et al. (1989), Am. Rev. Respir. Dis. 140 , 1693-1703.

100. Breit, S. N., Cairns, D., Szentirmay, A., et al. (1989), J. Rheumatol. 16, 1043-1049.

101. Gellert, A. R., Langford, J. A., Winter, R. J. D, et al. (1985), Thorax 40,508514.

102. De Vuyst, P., Jedwab, J., Dumortier, P., et al. (1982), Am. Rev. Respir. Dis. $126,972-976$

103. Robinson, B.W., Rose, A. H., James, A., et al. (1986), Chest 90, 396-102.

104. Begin, R., Bisson, G., Boileau, R., et al. (1986), Semin. Respir. Med. 7, 271280.

105. Chollet, S., Soler, P., Dournovo, P., et al. (1984), Am. J. Pathol. 115,225232.

106. Huang, M. S., Colby, T. V., Coellner, J. R., et al. (1989), Acta Cytol. 33,533538.

107. Martin, R. J., Coalson, J. J., Rogers, P. N., et al. (1980), Am. Rev. Respir. Dis. 121,819-825.

108. Dejaegher, P. and Demedts, M. (1984), Am. Rev. Respir. Dis. 129,631, 632.

109. Sherman, J. M.,Winnie, G.,Thomassen, M. J., et al. (1984), Chest 86, 409411.

110. Dorinsky, P. M., Davis, W. B., Lucas, J. G., et al. (1985), Chest 88, 58-63.

111. Kindt, G. C., Weiland, J. E., Davis, W. B., et al. (1989), Am. Rev. Respir. Dis. $140,483-492$.

112. Chastre, J., Fagon, J. Y., Soler, P., et al. (1989), Chest 95, 190S-192S.

113. Griffiths, M. H., Kocjan, G., Miller, R. F., et al. (1989), Thorax 44, 554-558.

114. Plaza, V., Jimenez, P., Xaubet, A. et al, (1989), Thorax 44, 289-291.

115. Guillon, J. M., Autran, S., Denis, M., et al. (1988), Chest 94, 1264-1270.

116. Mason, G. R., Hashimoto, C. H., Dickman, P. S., et al. (1989), Am. Rev. Respir. Dis. 139, 1336-1342.

117. Fleury-Feith, J., Tran Van Nhieu, J., Picard, C., et al. (1989), Chest 95, 1198-1201.

118. Young, Jr., R. K., Rankin, J. A, Naegel, G. P., et al. (1985), Ann. Int. Med. $103,522-533$.

119. Allen, K. A., Markin, R. S., Rennard, S. I., et al. (1989), Acta Cytol. 33, $539-543$.

120. Clelland, C. A., Higenbottam, T. W., Scott, J. P., et al. (1989), Thorax 44, 873. 
121. Milburn, H. J., Poulter, L. W., Prentice, H. G., et al. (1989), Thorax 44, 550575.

122. Prior, C., Klima, C., Gattringer, C., etal. (1989), Trans. Proc. 21,2588, 2589.

123. Harris, J. O., Olsen, G. N., Castle, J. R., et al. (1975), Am. Rev. Respir. Dis. $111,579-586$.

124. Chang, J. C., Lesser, M., Yoo, O. H., et al. (1980), Lung 157, 135-142.

125. Chang, J. C., Yoo, O. H., and Lesser, M. (1989), Am. Reu. Respir. Dis. 140 , $958-960$.

126. Church, D. F. and Pryor, W. A. (1985), Environ. Health Perspect. 64, 111-126.

127. Cantin, A. M., North, S. L., Huggard, R. C., et al. (1987), J. Appl. Physiol. $63,152-157$.

128. Heffner, J. E. and Repine, J.E. (1989), Am. Rev. Respir. Dis. 140,531-554.

129. Frei, B., England, L., and Ames, B. N. (1989), Proc. Natl. Acad. Sci. USA 86, 6377-6381.

130. Buhl, R., Hubbard, R., Crittenden, M., et al. (1989), Am. Rev. Respir. Dis. 139, A475.

130a. Aguayo, S. M., Kane, M. A., King, T. E., et al. (1989), J. Clin. Invest. 84, 1105-1113.

131. Cross, C. E., Frei, B., and Louie, S. (1990), in Antioxidants in Therapy and Preventive Medicine (Emerit, I. and Packer, L., eds.), Plenum, in press.

132. Cross, C. E., Forte, T., Stocker, R, et al. (1990), J. Lab. Clin. Med. 115 , $396-404$.

133. Montgomery, A. B., Stager, M. A., Carrico, J., et al. (1986), Am. Rev. Respir. Dis. 132, $485-489$.

134. Fick,Jr., R. B., Richerson, H. B., Zavala, D. C., etal. (1987), Am. Rev. Respir. Dis. 136, 1204-1209.

135. Wardlaw, A. J., Collins, J. V., and Kay, A. B. (1987), Int. Arch. Allergy Appl. Immunol. 82, 618-626.

136. Kirby, J. G., Hargreave, F. E., Gleich, G. J., et al. (1987), Am. Rev. Respir. Dis. 136, 379-383.

137. Wardlaw, A.J., Hay, H., Cromwell, O, et al. (1989), J. Allergy Clin. 84, 1926.

138. Diaz, P., Gonzalea, M. C., Galleguillos, F. R. et al. (1989), Am. Rev. Respir. Dis. 139, 1383-1389.

139. Wenzel, S. E., Fowler, III, A. A., and Schwartz, L. (1988), Rev. Respir. Dis. 137, 1002-1008.

140. Pliss, L. B., Ingentito, E. P., Ingram, Jr. R. H. (1989), J. Appl. Physiol. 66, 2298-2304.

141. Fuller, R. W. (1989), Respir. Med. 83, 177, 178.

142. Alpert, S. M., Schwarts, B. B., Lee, S. D., et al. (1971), Arch. Intern. Med. 128,69-73.

143. Bassett, J. P., Bowen-Kelly, E., Brewster, E. L., et al. (1988), Lung 166, 355-369.

144. Guth, D. J., Warren, D. L., and Last, J. A. (1986), Toxicol. 40, 131-143.

145. Hatch, G. E., Slade, R., Stead, A. G., et al. (1986), J. Toxicol. Envir. Health 19,43-53.

146. Glauser, F. L., Bechard, D. E., Fisher, B. J., et al. (1988), Am.J. Path. 131, $404-410$.

147. Hampson, E. C. G. M., Eyles, D. W., and Pond, S. M. (1989), Toxicol. Appl. Pharm. 98, 206-215. 